\title{
Effect of HDL level on thrombus resolution in pulmonary embolism
}

\author{
Mükremin ER ${ }^{1}$, Gökhan AYKUN² ${ }^{2}$ Ayşegül KARALEZLI' ${ }^{3}$ H. Canan HASANOĞLU³
}

\footnotetext{
${ }^{1}$ Department of Chest Diseases, Ankara Ataturk Training and Research Hospital, Ankara, Turkey.

${ }^{2}$ Department of Chest Diseases, Tokat Medical Park Hospital, Tokat, Turkey.

${ }^{3}$ Department of Chest Diseases, Ankara Yıldırım Beyazıt University, School of Medicine, Ankara, Turkey.
}

\section{SUMMARY}

Recurrent thrombosis and lack of enough resolution of pulmonary emboli may lead to the development of chronic thromboembolic pulmonary hypertension. The purpose of this study was to investigate the correlation of initial, 10th-day and 6th-month lipid profile values with the changes in the pulmonary artery obstruction index in patients with pulmonary embolism (PE).

Twenty-eight patients diagnosed with PE were included in the study. Fifteen of them were treated using thrombolytic agents, and 13 of them were treated using conventional treatment. Pulmonary artery obstruction index of all patients was calculated after they underwent pulmonary computed tomography (CT) angiography. Arterial blood gas analysis and echocardiography were performed and lipid profile levels were analyzed during initial diagnosis and repeated on the 10th day and 6 th month of the treatment.

A significant positive correlation was found between HDL and percent change in pulmonary artery obstruction index. The patients with a high level of HDL showed better emboli resolution $(P=0.013)$. Higher age and lower percent change in the 10th-day pulmonary artery obstruction showed a positive correlation with the persistence of embolism in the 6th month.

Patients with lower HDL levels are at risk of recurrent embolic events and even chronic thromboembolic pulmonary hypertension, which can be prevented by HDL augmentation.

Keywords: Chronic thromboembolic pulmonary hypertension, conventional anticoagulation therapy, high-density lipoprotein, pulmonary artery obstruction index, pulmonary embolism, pulmonary computed tomography angiography, thrombolytic therapy

\section{INTRODUCTION}

Pulmonary embolism (PE) is a major cause of death during admissions to the emergency department. Besides mortality and morbidity that occur in the acute phase, the second problem faced by patients with PE is chronic thromboembolic pulmonary hypertension (CTEPH), which is found to be more frequent than what was formerly believed. A recent study showed that the incidence of CTEPH was 3.8\% within 2 years after the acute attack (1). Another study showed that the 3-year mortality was $90 \%$ in patients with the average pulmonary arterial pressure of more than $30 \mathrm{~mm} \mathrm{Hg}(2)$.

The causes of CTEPH in PE include lack of enough resolution of thrombi when the pulmonary artery is occluded or partially occluded by thrombus for more than 6 months and recurrent thrombosis (3).

In the present study, thorax pulmonary computed tomography (CT) angiography was applied to patients with submassive PE initially on the 10th day and in the 6th month of treatment to evaluate the clinical and laboratory factors affecting thrombus resolution and find a way to avoid CTEPH development. 


\section{MATERIALS AND METHODS}

This study was a prospective case-control clinical study approved by the local ethics committee (May 13, 2009; 2002-4/3). All patients or relatives provided written consent to participate in the study.

A total of 28 patients diagnosed with PE using pulmonary CT angiography, as well as submassive PE (based on clinical and laboratory findings), were selected from the clinic of pulmonary diseases.

The study was conducted on patients diagnosed with PE using pulmonary CT angiography. The pulmonary artery obstruction index (PAOI) of all patients was calculated using a formula by a radiologist. Electrocardiography $(E C G)$ and echocardiography $(E C H O)$ were applied to all patients. Additionally, D-dimer, venous blood samples for analyzing lipid profiles, and arterial blood gases (ABG) were also evaluated. Demographic characteristics of the patients, the interval from the onset of symptoms to start of treatment, laboratory results, $A B G, P A O I, E C H O$ results, and pulmonary arterial pressure (PAP) were all recorded on a detailed data sheet. On the 10th day and in the 6th month of the treatment, D-dimer and lipid profiles, $A B G$, and transthoracic $E C H O$ were repeated and the results were recorded. CT angiography was performed on all patients initially during therapy and repeated on the 10th day. The sixth-month follow-up CT angiography was applied to 19 patients because 6 of them had changed their hospital and 3 of them had kidney failure. The laboratory results of $\mathrm{CT}$ and ECHO on the 10th day and in the 6th month of the treatment were compared. ABG, PAP, and cholesterol panel were analyzed to investigate the presence of any factor affecting the embolism resolution rate on the 10th day and in the 6th month of the treatment.

Patients aged less than 18 years, pregnant women, those with renal impairment or those who could not undergo CT angiography for any other reason were excluded from the study.

Thirty patients with PE, having the PAOI more than $35 \%$, received thrombolytic therapy. Patients treated with thrombolytic agents were classified as group 1. The remaining 13 patients were not considered for thrombolytic treatment due to a relative or absolute contraindication; they underwent conventional anticoagulation therapy. These thirteen conventionally treated patients were classified as group 2. All of the patients were in the submassive embolism group.

Pulmonary CT angiography was performed by Aquillion 64(Toshiba, Tokyo, Japan; $64 \times 0.5 \mathrm{~mm}^{2}$ collimation with a 0.5-s rotation time; $3.5 \mathrm{~cm} / \mathrm{s}$ gantry rotation table movement, and 200 $\mathrm{mA}$ and $120 \mathrm{kV}$ on average). The contrast material was injected

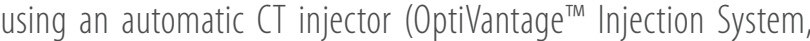
Tyco Healthcare Mallinckrodt, St Louis, United States). The contrast medium ( $80 \mathrm{~mL}$ ) was injected into the forearm vein of all patients under medical supervision at the injection rate of $4 \mathrm{~mL} / \mathrm{s}$. For all patients, 75\% iohexol (Omnipaque 350, Amersham Health, Cork, Ireland) was used as the contrast material. Diagnostic imaging was performed using "sure start" software (Toshiba, Tokyo, Japan) and automated bolus triggering method. Diagnostic imaging started automatically when the attenuation value reached $150 \mathrm{HU}$ at the region of interest in the main pulmonary artery.

The pulmonary artery obstruction index was calculated by a radiology specialist according to the formula [PAOI $=\sum($ nd $) / 40 \times$ 100] developed by Qanadli et al. and proved in many studies (4).

The PAOI was calculated by the radiologist. On the 10th day and in the 6th month of the treatment, the resolution ratio was obtained using the following formula:

PAOI (\%) change $=(($ PAOI on the 1st day of PAOI - PAOI on the 10th day $) /$ PAOl on the 1 st day) $\times 100$

ECHO was taken using the "Vivid 7 Pro" brand device, and the results were recorded. Improvement in $\mathrm{ABG}$ and $\mathrm{ECHO}$ results on the 10th day was expressed as the percent change. The results were calculated using the following formulas:

$p \mathrm{CO}_{2}(\%)$ change $=\left(10\right.$ th-day $\mathrm{pCO}-1$ st-day $\mathrm{pCO} \mathrm{CO}_{2} / 1$ st-day day $\left.\mathrm{pCO} \mathrm{CO}_{2}\right) \times 100$ $\mathrm{pO}_{2}(\%)$ change $=\left(10\right.$ th-day $\mathrm{pO}_{2}-1$ st-day $\left.\mathrm{PO}_{2}\right) / 1$ st-day $\left.\mathrm{pO}_{2}\right) \times 100$ $\mathrm{SaO}_{2}(\%)$ change $=\left(10\right.$ th-day $\mathrm{SaO}_{2}-1$ st-day $\left.\mathrm{SaO}_{2}\right) / 1$ st-day $\left.\mathrm{SaO}_{2}\right) \times 100$ $\operatorname{PAP}(\%)$ change $=(10$ th-day PAP -1 st-day PAP $) / 1$ st-day PAP $) \times 100$

\section{Statistical analysis}

CThe characteristics of patients were summarized using basic statistical methods. For descriptive purposes, quantitative variables were presented as mean \pm standard deviation (SD). 
Patients belonging to the two groups were compared using the Fisher's exact test for dichotomous variables and the Wilcoxon rank test for continuous variables. The impact of laboratory test parameters on PAOI values before and after treatment was analyzed as univariate using the Fisher's exact test. The chi-square test was used for categorical variables. SD, median, minimum, and maximum values were used for summarizing the average of numeric parameters, whereas numbers and percentages were used for categorical variables. Significance tests of the study were two sided, with a $P$ value $P<0.05$ indicating clinical significance. Statistical analyses were performed using SPSS (SPSS Inc., Chicago, IL) 16.0 software.

\section{RESULTS}

A total of 28 patients with submassive embolism, aged 29-83 years, were investigated in this study. Thrombolytic treatment was given to 15 patients, whereas the remaining patients were conventionally treated. A comparison of characteristics of these patients is shown in Table 1. No statistical meaningful difference was observed between groups.

The correlation between vascular occlusion resolution rate percentage and other parameters of all patients on the 10th day of the treatment are shown in Table 2. A significant positive correlation was found between HDL and PAOI (\%) change. These results showed a significant correlation between the high amount of HDL and emboli resolution.

The correlation between HDL level and PAOI (\%) change is schematically depicted in Figure 1. The figure shows that the PAOI opening rate on the 10th day increased with an increase in the HDL level.

As a correlation between the HDL level and the PAOI opening rate on the 10th day was observed, a new group was formed including the patients with normal and low levels of HDL. PAOI (\%) change, $A B G$, and PAP values for both groups are shown in Table 3. Thrombus resolution was more in the group with HDL $\geq 40 \mathrm{mg} / \mathrm{dL}$ than in the group with $\mathrm{HDL}<40 \mathrm{mg} / \mathrm{dL}$, but with no statistical significance.

No statistically significant correlation was found between the initial PAOI and percent change on the 10th day. However, any delay in the initiation of the treatment caused a decrease in PAOI
TABLE 1: Comparison of the characteristics of all patients.

\begin{tabular}{lccc}
\hline Characteristics & $\begin{array}{c}\text { Group 1 \# } \\
(n=15) \\
\text { mean } \pm \text { SE }\end{array}$ & $\begin{array}{c}\text { Group 2 \$ } \\
(n=13)\end{array}$ & mean \pm SE \\
\hline Gender (M/F) & $6 / 9$ & $4 / 9$ & 0.258 \\
Age (years) & $59.9 \pm 17$ & $58.8 \pm 15.9$ & 0.627 \\
Admission time (day) & $7.2 \pm 8.7$ & $8.0 \pm 8.1$ & 0.671 \\
Onset day of therapy & $8.4 \pm 8.8$ & $8.0 \pm 8.1$ & 0.643 \\
Initial PAOI (\%) & $57.3 \pm 7.3$ & $52.0 \pm 10.0$ & 0.342 \\
Initial CHOL(mg/dL) & $192.2 \pm 43.1$ & $183.1 \pm 39.8$ & 0.563 \\
Initial LDL (mg/dL) & $118.4 \pm 32.2$ & $113.8 \pm 27.1$ & 0.401 \\
Initial HDL (mg/dL) & $44.7 \pm 14.3$ & $39.5 \pm 7.5$ & 0.207 \\
Initial TG (mg/dL) & $142.0 \pm 56.7$ & $145.5 \pm 71.2$ & 0.358 \\
\hline \#Group 1: All patients received thrombolytic therapy. & \\
\$Group 2: All patients received conventional therapy. & \\
CHOL: Total Cholesterol, HDL: High-density lipoprotein, & \\
LDL: Low-density lipoprotein, PAOI: Pulmonary artery obstruction index, \\
TG: Triglyceride
\end{tabular}

TABLE 2: Correlation between PAOI (\%) and other parameters for all patients.

\begin{tabular}{|c|c|c|}
\hline Characteristics & Correlation coefficient & $P$ value \\
\hline Age (years) & -0.286 & 0.140 \\
\hline Initial PAOI (\%) & -0.330 & 0.087 \\
\hline Onset day of therapy & -0.283 & 0.144 \\
\hline Initial $\mathrm{pCO}_{2}(\mathrm{mmHg})$ & -0.302 & 0.119 \\
\hline Initial $\mathrm{pO}_{2}(\mathrm{mmHg})$ & 0.068 & 0.733 \\
\hline Initial $\mathrm{SaO}_{2}(\%)$ & -0.031 & 0.875 \\
\hline Initial PAP (mmHg) & $-0,103$ & 0.602 \\
\hline D-dimer (mg/dL) & 0,011 & 0.957 \\
\hline $\mathrm{CHOL}(\mathrm{mg} / \mathrm{dL})$ & 0,282 & 0.146 \\
\hline $\mathrm{LDL}(\mathrm{mg} / \mathrm{dL})$ & 0,301 & 0.119 \\
\hline Triglyceride (mg/dL) & $-0,169$ & 0.391 \\
\hline
\end{tabular}

*Statistically significant.

CHOL: Total Cholesterol, HDL: High-density lipoprotein, LDL: Low-density lipoprotein, PAOI: Pulmonary artery obstruction index, PAP: Pulmonary artery pressure, $\mathrm{pCO}_{2}$ : Partial arterial carbondioxide, $\mathrm{pO}_{2}$ : Partial arterial oxygen, $\mathrm{SaO}_{2}$ : Saturated arterial oxygen, TG: Triglyceride

(\%) change on the 10th day. This correlation is shown in Figure 2. No statistically significant correlation was observed between PAOI (\%) change and gender.

A negative correlation was found between age and PAOI (\%) change on the 10th day, with no statistical significance. Figure 3 shows 


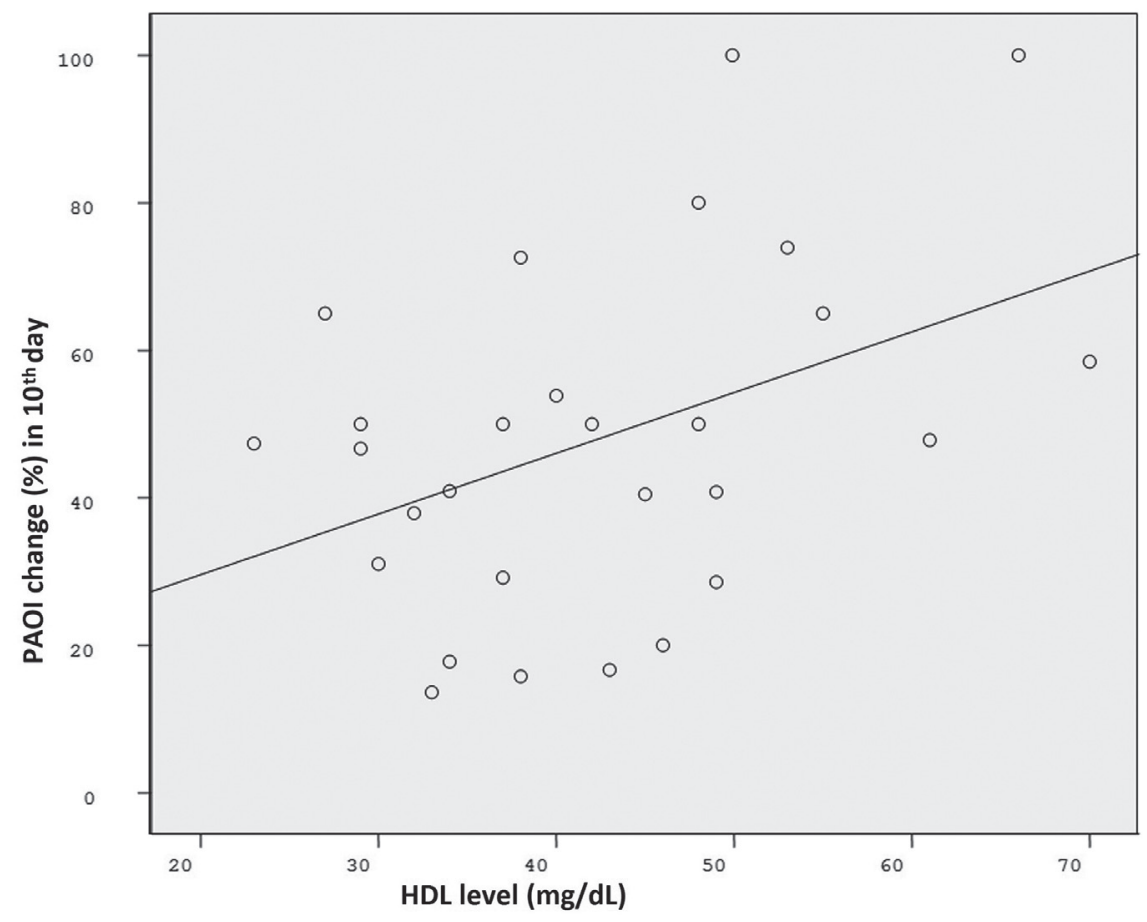

FIGURE 1: Correlation between HDL level and PAOI (\%) change in all patients on the 10th day of treatment.

that the PAOI (\%) change decreased with aging in both treatment groups.

The persistence of embolism was observed in 3 of 19 patients who underwent control tests in the sixth month of the treatment. A correlation between old age and low PAOI (\%) change on the 10th day was observed in three patients with persistent PE, but statistical tests could not be applied due to a large difference between the two patient groups as shown in Table 4. Although specified parameters were associated with the persistence of embolism in the sixth month, no parameter could assist in predicting persistent embolism in patients.

\section{DISCUSSION}

A low HDL level is considered as a risk factor for venous thromboembolism (VTE). Moreover, statins are believed to have a protective role in the development of VTE. Although the relationship between HDL level and VTE occurrence has

TABLE 3: Comparison of (\%) changes in PAOI, ABG, and PAP values between two groups defined by HDL levels.

\begin{tabular}{|c|c|c|c|c|c|}
\hline & \multicolumn{2}{|c|}{$\begin{array}{c}\mathrm{HDL} \geq 40 \mathrm{mg} / \mathrm{dl} \\
(n=15)\end{array}$} & \multicolumn{2}{|c|}{$\begin{array}{c}\mathrm{HDL}<40 \mathrm{mg} / \mathrm{dl} \\
(n=13)\end{array}$} & \multirow[b]{2}{*}{$P$ value } \\
\hline & Mean \pm SD & Median & Mean \pm SD & Median & \\
\hline Initial PAOI (\%) & $52.9 \pm 9.1$ & 52.5 & $57.0 \pm 8.5$ & 55.0 & 0.236 \\
\hline PAOI (\%) change & $55.1 \pm 25.3$ & 50.0 & $39.5 \pm 18.3$ & 41.0 & $0.077^{*}$ \\
\hline $\mathrm{pCO}_{2}(\%)$ change & $30.2 \pm 4.1$ & 29.9 & $30.6 \pm 7.3$ & 30.2 & 0.861 \\
\hline $\mathrm{pO}_{2}(\%)$ change & $56.8 \pm 10.6$ & 55.8 & $51.6 \pm 11.8$ & 51.2 & 0.239 \\
\hline $\mathrm{SaO}_{2}(\%)$ change & $88.4 \pm 8.0$ & 90.8 & $85.1 \pm 9.1$ & 87.8 & 0.322 \\
\hline PAP (\%) change & $50.3 \pm 13.6$ & 50.0 & $56.3 \pm 9.4$ & 60.0 & 0.196 \\
\hline
\end{tabular}

* Thrombus resolution is more in the group having $\mathrm{HDL} \geq 40 \mathrm{mg} / \mathrm{dl}$, but it was not statistically significant.

PAOI: Pulmonary artery obstruction index, PAP: Pulmonary artery pressure, $\mathrm{pCO}_{2}$ : Partial arterial carbondioxide, $\mathrm{pO}_{2}$ : Partial arterial oxygen, $\mathrm{SaO}_{2}$ : Saturated arterial oxygen, TG: Triglyceride 


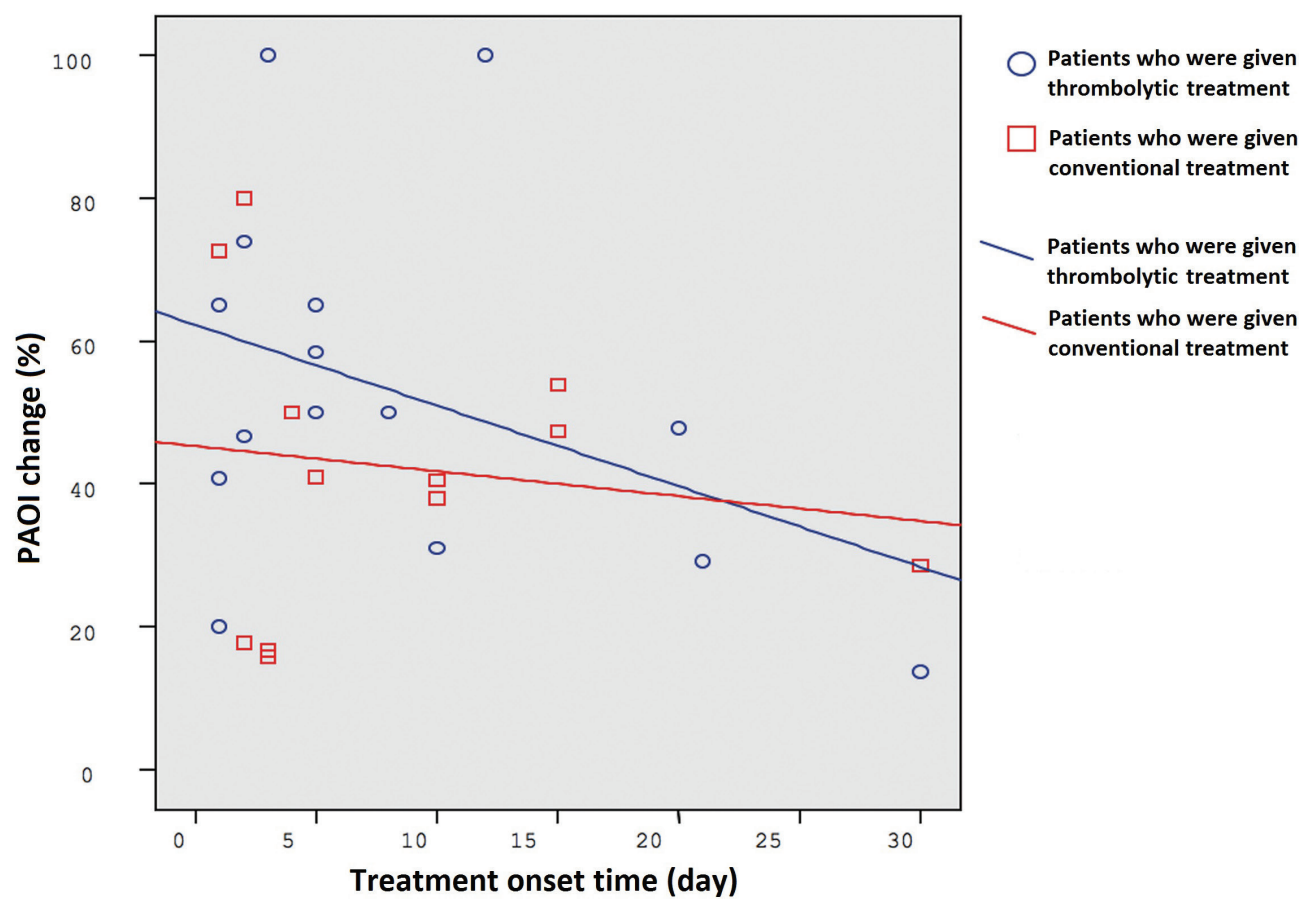

FIGURE 2: Correlation between onset day of the treatment and PAOI (\%) change on the 10th day of treatment.

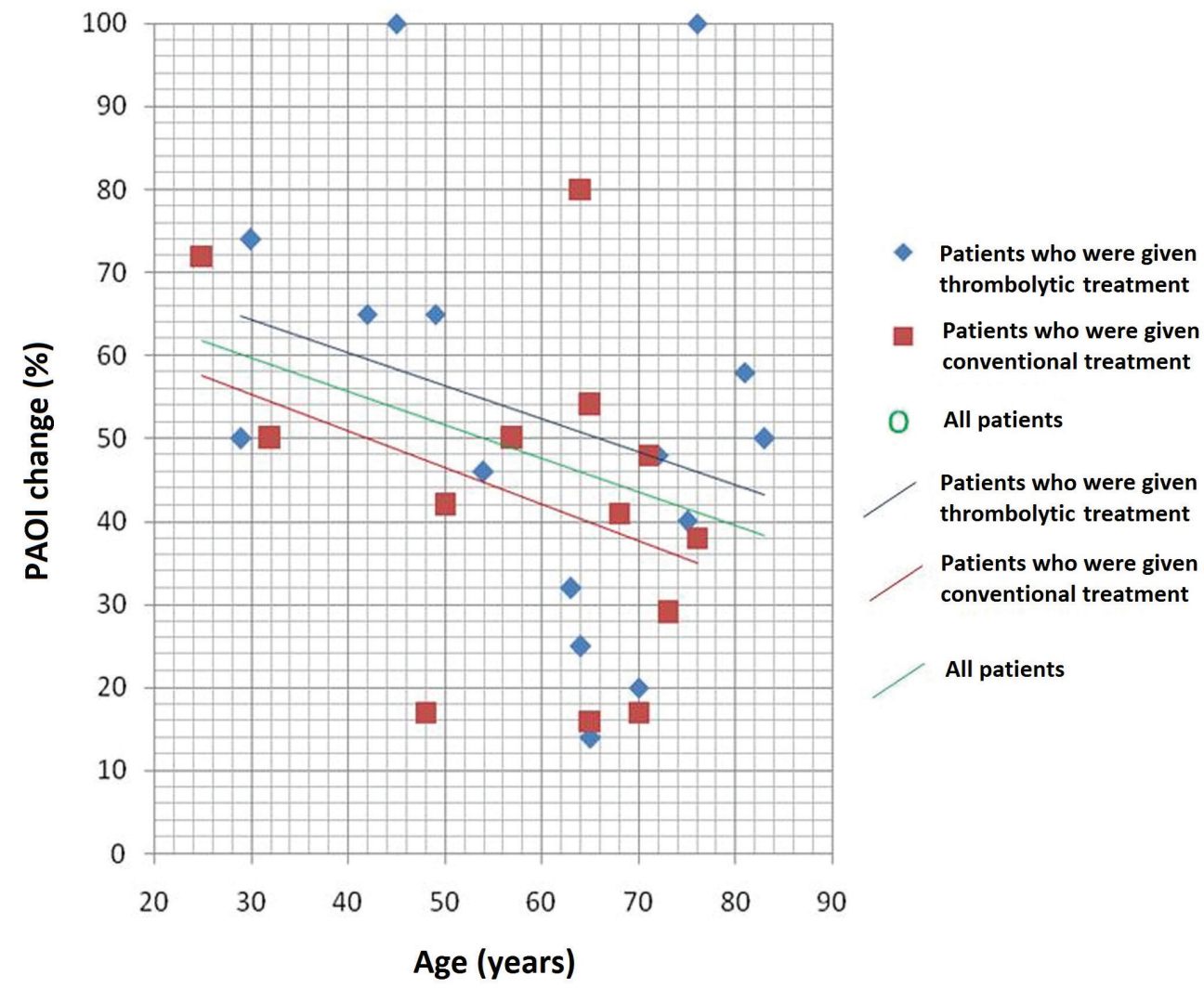

FIGURE 3: Correlation between age and PAOI (\%) change for patients who received thrombolytic therapy, those who received conventional therapy, and all of both group patients on the 10th day of treatment. 
TABLE 4: Comparison of the characteristics of the patients not diagnosed with PE versus those diagnosed with PE during the sixthmonth follow-up

\begin{tabular}{|c|c|c|c|}
\hline Characteristics & $\begin{array}{l}\text { PE }(-) \text { at } 6 \text { th month } \\
(n=16) \\
\text { mean } \pm \text { SD }\end{array}$ & $\begin{array}{c}\mathrm{PE}(+) \text { at } 6 \text { th month } \\
(n=3) \\
\text { mean } \pm \mathrm{SD}\end{array}$ & $P$ value \\
\hline Gender (M/F) & $7 / 9$ & $1 / 2$ & $p>0.05$ \\
\hline Age (years) & $56.8 \pm 17.2$ & $70.6 \pm 5.9$ & $P<0.05^{*}$ \\
\hline Onset day of therapy & $6.8 \pm 7.5$ & $17.3 \pm 14.8$ & $p>0.05$ \\
\hline Initial PAOI (\%) & $54.5 \pm 10.1$ & $58.3 \pm 5.2$ & $p>0.05$ \\
\hline PAOI (\%) 10th day & $24.9 \pm 15.3$ & $39.0 \pm 3.0$ & $P<0.05^{*}$ \\
\hline PAOI (\%) change & $55.0 \pm 26.2$ & $31.3 \pm 7.8$ & $P<0.05^{*}$ \\
\hline PAOI (\%) 6th month & $0.0 \pm 0.0$ & $13.3 \pm 5.7$ & $P<0.05^{*}$ \\
\hline Initial $\mathrm{pO}_{2}(\mathrm{mmHg})$ & $55.4 \pm 11.9$ & $55.0 \pm 8.8$ & $p>0.05$ \\
\hline Initial $\mathrm{pCO}_{2}(\mathrm{mmHg})$ & $29.8 \pm 7.4$ & $31.4 \pm 7.2$ & $p>0.05$ \\
\hline Initial $\mathrm{SaO}_{2}(\mathrm{mmHg})$ & $86.7 \pm 10.3$ & $88.2 \pm 4.3$ & $p>0.05$ \\
\hline Initial PAP (mmHg) & $53.0 \pm 11.7$ & $44.3 \pm 7.5$ & $p>0.05$ \\
\hline D-dimer (mg/dL) & $4870.3 \pm 1963.8$ & $4772.3 \pm 1819.0$ & $p>0.05$ \\
\hline Cholesterol (mg/dL) & $184.4 \pm 42.5$ & $178.7 \pm 37.3$ & $p>0.05$ \\
\hline $\mathrm{LDL}$ (mg/dL) & $112.5 \pm 29.5$ & $100.0 \pm 16.6$ & $p>0.05$ \\
\hline $\mathrm{HDL}(\mathrm{mg} / \mathrm{dL})$ & $43.8 \pm 12.2$ & $45.0 \pm 6.9$ & $p>0.05$ \\
\hline Triglyceride (mg/dL) & $137.7 \pm 64.8$ & $164.0 \pm 83.6$ & $p>0.05$ \\
\hline
\end{tabular}

* Statistically significant

CHOL: Total Cholesterol, HDL: High-density lipoprotein, LDL: Low-density lipoprotein, PAOI: Pulmonary artery obstruction index,

PAP: Pulmonary artery pressure, $\mathrm{pCO}_{2}$ : Partial arterial carbondioxide, $\mathrm{pO}_{2}$ : Partial arterial oxygen, $\mathrm{SaO}_{2}$ : Saturated arterial oxygen, TG: Triglyceride

been shown, the relationship between HDL level and embolism resolution or CTEPH development is still unknown. Although statins are commonly used in arterial thrombosis, its use in preventing and treating VTE is not recommended at this stage.

In their follow-up controls, Pengo et al. diagnosed 7 patients with CTEPH among 223 patients with PE. They identified the risk factors for the development of CTEPH as previous PE, younger age, serious perfusion defects, and idiopathic PE (1).

In the present study, 6 of 56 patients had persistent, albeit reduced, PE in the sixth-month control. The patients with a persistent embolism in the 6th-month CT were generally older patients, the ones who received treatment late or the ones who had lesser resolution ratios in the 10th-day control. Old age and lower PAOI (\%) change over 10 days were detected to have a statistically significant positive correlation with the persistence of emboli in the sixth month. Nevertheless, the positive correlation between the late start of treatment and persistence of emboli in the sixth month was not statistically significant.

Gender, PAOI development, ABG and ECHO results, D-dimer, and lipid profiles were found to have no correlation with the persistence of emboli in the sixth month. Patients with a history of PE were not included in this study and hence higher CTEPH development rates could not be evaluated in these patients, as reported by Pengo et al.1. Younger age was believed to be a risk factor for CTEPH development, contradicting the results of the present study. Moreover, it was concluded that CTEPH development was more common in patients with a larger perfusion defect, which was also incompatible with the results of the present study. As mentioned previously, scintigraphy was used to determine perfusion defect rate, which was not as sensitive and accurate as CT used to determine the PAOI rate. Idiopathic PE is known to be a risk factor for CTEPH development. 
The likelihood ratio was reported as 5.7 and the number of younger patients with idiopathic PE was not specified in the aforementioned study. The fact that younger patients were the ones with idiopathic PE might have affected the results.

Whether the developed PE would be resolved or it might cause the development of CTEPH is still unknown. Since which patients may show a slower rate of PE resolution is not known, it is recommended that the development of pulmonary hypertension in these patients can be monitored using echocardiography (5).

In the present study, the rate and influencing factors of emboli resolution were investigated. The average 10th-day emboli resolution rate was $49.9 \% \pm 19.7 \%$ for 10 male patients and $46.9 \pm 25.4 \%$ for 18 female patients. The difference between these two values was not statistically significant, indicating that gender was not a determining factor. A negative correlation was observed between age and emboli resolution; the 10th-day emboli resolution decreased with age. However, this correlation was also found to be statistically insignificant.

The time period from onset of the disease until the inception of treatment showed a negative correlation with the 10th-day emboli resolution, which was statistically insignificant. Control $P A O I, A B G$, and $E C H O$ results, and the levels of D-dimer, total cholesterol, low-density lipoprotein (LDL), and triglycerides were found to have no correlation with the 10th-day emboli resolution in the study.

Ageno et al. meta-analyzed 5 studies covering a total of 895 cases and 9841 controls. They reported a negative correlation between HDL level and development of VTE (6).

The HDL level is vital in the development of PE, and previous studies have shown a correlation between low HDL level and development of emboli (7-11). Wang et al. also reported that pulmonary arterial trunk embolism was negatively correlated with the level of HDL cholesterol (11). The risk factors for VTE recurrence during anticoagulation include immobilization, cancer, and chronic obstructive pulmonary disease. The risk factors for recurrence after anticoagulation include male gender, elevated body mass index, low levels of HDL cholesterol, and initial presentation with symptomatic PE rather than symptomatic deep vein thrombosis (DVT) $(12,13,14,15)$. Moreover, numerous studies have demonstrated the role of statin treatment in reducing the development of emboli, although the underlying mechanism is still unknown (16-18). Among all studies on thromboembolism, the JUPITER study is an important one in which 17802 healthy volunteers with normal lipid profile were randomized to take $20 \mathrm{mg} /$ day rosuvastatin or placebo and were under follow-up controls for the average of 1.9 years. At the end of the study, the group using statin was observed to have lower symptomatic DVT and PE. However, the effect of lipid profile on the resolution of embolism was unknown (16). In the present study, total cholesterol, LDL, and triglyceride levels were found to have no correlation with the resolution of embolism, whereas HDL level affected the 10th-day emboli resolution. High levels of HDL were found to have a statistically significant positive correlation with the PAOI opening rate. Considering all groups, the initial PAOI and the opening rate were $57.6 \% \pm 8.4 \%$ and $40.8 \% \pm 17.9 \%$, respectively, for 14 patients with HDL level $<40$ (average 32.9). The same values for 14 other patients with HDL level $>40$ (average 51.7) were $52.1 \% \pm 8.9 \%$ and $55.1 \%$ $\pm 26.4 \%$, respectively. These clinical findings were reported for the first time in the literature. However, an experimental study showed that an apoA-I (Apolipoprotein A-I) (HDL)-SR-BI (The scavenger receptor B type I)-eNOS (endothelial NO synthase enzyme) axis was highly protective in DVT and might provide new targets for prophylaxis and treatment of venous thrombosis (19). A correlation between the sixth-month emboli persistence and HDL levels could not be detected due to the small number of patients.

\section{CONCLUSIONS}

The present study reported a correlation of PAOI\% change and emboli resolution with the onset of treatment and age of the patient. On the contrary, the HDL level was found to be positively correlated with emboli resolution. Therefore, patients with higher HDL levels may have better resolution of the embolism and the patients with low levels of HDL may have a risk particularly for the development of CTEPH. Therefore, nutrition and treatments that might help to increase the HDL level should be evaluated in terms of preventing and treating PE. 


\section{REFERENCES}

1. Pengo $V$, Lensing $A W$, Prins $M H$, Marchiori $A$, Davidson $B L$, Tiozzo F, et al. Incidence of chronic thromboembolic pulmonary hypertension after pulmonary embolism. N Engl J Med 2004; 350:2257-2264.

2. Lewczuk J, Piszko P, Jagas J, Porada A, Wojciak S, Sobkowicz B, et al. Prognostic factors in medically treated patients with chronic pulmonary embolism. Chest 2001; 119:818-823.

3. Bonderman D, Lang Irene M. Risk Factors for Chronic Thromboembolic Pulmonary Hypertension. Textbook of Pulmonary Vascular Disease. Yuan JX-J, Garcia JGN, Hales CA, Rich S, Archer SL, West JB (Eds.). Springer. 2011;pp 1253-1259.

4. Qanadli SD, Hajjam ME, Baron AV, Joseph T, Mesurolle B, Oliva $\mathrm{VL}$, et al. New CT Index to Quantify Arterial Obstruction in Pulmonary Embolism: Comparison with Angiographic Index and Echocardiography. AJR 2001; 176:1415-1420.

5. Ribeiro $A$, Lindmarker $P$, Johsson $H$, Dannfelt $A J$, Jorfeldt L. Pulmonary Embolism: One-Year Follow-Up with Echocardiography Doppler and Five-Year Survival Analysis. Circulation 1999; 99:1325-1330.

6. Ageno W, Becattini C, Brighton T, Selby R, Kamphuisen PW. Cardiovascular Risk Factors and Venous Thromboembolism: A Meta-Analysis. Circulation 2008; 117:93-102.

7. Eichinger S, Pecheniuk NM, Hron G, Deguchi $H$, Schemper M, Kyrle PA, et al. High-Density Lipoprotein and the Risk of Recurrent Venous Thromboembolism. Circulation 2007; 115:1609-1614

8. Carine JM, Nicholas LS, Rozenn NL, Susan RH, Frits RR, Bruce MP. Serum Lipid Levels and the Risk of Venous Thrombosis. Arterioscler Thromb Vasc Biol 2004; 24:1970-1975.

9. Karalezli A, Parlak ES, Kanbay A, Senturk A, Hasanoglu HC. Homocysteine and serum-lipid levels in pulmonary embolism. Clin Appl Thromb Hemost 2011; 17(6):E186-9.

10. Albert CM, Ma J, Rifai N, Stampfer MJ, Ridker PM. Prospective study of C-reactive protein, homocysteine, and plasma lipid levels as predictors of sudden cardiac death. Circulation. 2002; 105(22):2595-9.
11. Wang Y, Wang P, Li H. Correlation study of pulmonary embolism and high-density lipoprotein cholesterol. Clin Cardiol 2010; 33(2):72-6.

12. Goldhaber SZ, Piazza G. Optimal duration of anticoagulation after venous thromboembolism. Circulation 2011; 123(6):664-7.

13. Zee RY, Mora S, Cheng S, Erlich HA, Lindpaintner K, Rifai N, Buring JE, Ridker PM. Homocysteine, 5,10-methylenetetrahydrofolate reductase $677 \mathrm{C}>\mathrm{T}$ polymorphism, nutrient intake, and incident cardiovascular disease in 24,968 initially healthy women. Clin Chem. 2007; 53(5):845-51.

14. Belaj K, Hackl G, Rief P, Eller P, Brodmann M, Gary T. Changes in Lipid Metabolism and Extension of Venous Thromboembolism. Ann Nutr Metab 2014; 64:122-126. (DOI:10.1159/000360484)

15. Clive Kearon, $\mathrm{MD}, \mathrm{PhD}$; Elie $\mathrm{A}$ Akl, $\mathrm{MD}, \mathrm{MPH}, \mathrm{PhD}$; Joseph Ornelas, PhD; Allen Blaivas, DO, FCCP; David Jimenez, MD, PhD, FCCP; Henri Bounameaux, et al. Antithrombotic Therapy for VTE Disease: CHEST Guideline and Expert Panel ReportChest. 2016;149(2):315-352. doi:10.1016/j.chest.2015.11.026

16. Glynn RJ, Danielson E, Fonseca FA, Genest J, Gotto AM, Kastelein $J$ J, et al. A Randomized Trial of Rosuvastatin in the Prevention of Venous Thromboembolism: the JUPITER Trial. N Engl J Med 2009; 360:1851-1861.

17. Ramcharan AS, Stralen KJ, Snoep JD, Teeuwisse AK, Rosendaal FR, Doggen CJ. HMG-CoA reductase inhibitors, other lipidlowering medication, anti platelet therapy, and the risk of venous thrombosis. Journal of Thrombosis and Haemostasis 2008; 7:514-520.

18. Ray JG, Mamdani M, Tsuyuki RT, Anderson DR, Teo EL, Laupacis A. Use of Statins and the Subsequent Development of Deep Vein Thrombosis. Arch Intern Med 2001; 161:1405-1410.

19. Brill A, Yesilaltay A, De Meyer SF, Kisucka J, Fuchs TA, Kocher O, Krieger M, Wagner DD. Extrahepatic High-Density Lipoprotein Receptor SR-BI and ApoA-I Protect Against Deep Vein Thrombosis in Mice. Arteriosclerosis, Thrombosis, and Vascular Biology 2012; 32:1841-1847. 